\title{
Splenic Rhythms and Postprandial Dynamics in Physiology, Portal Hypertension, and Functional Hyposplenism: A Review
}

\author{
Johannes Weinzirl ${ }^{\mathrm{a}} \quad$ Lydia Garnitschnig $^{\mathrm{a}}$ Tom Scheffers $^{\mathrm{a}} \quad$ Lukas Andrae $^{\mathrm{b}}$ \\ Peter Heusser ${ }^{a}$ \\ anstitute for Integrative Medicine, Faculty of Health, Witten/Herdecke University, Herdecke, Germany; \\ ${ }^{b}$ Department of Internal Medicine, Community Hospital Herdecke, Herdecke, Germany
}

\section{Keywords}

Splanchnic circulation · Digestion · Postprandial

hyperaemia $\cdot$ Portal hypertension · Functional

hyposplenism

\begin{abstract}
Background: Before the discovery of immunological and haematological functions of the spleen, it had for centuries been considered to be a digestive organ of variable size with a role in the portal vein system and nutritional metabolism. In the 19th and 20th centuries, volume changes in the spleen related to nutrition were studied using plethysmographic measurements. Rhythmical and regulatory functions of the spleen were demonstrated in the haemodynamics of the splanchnic region and were described as a "hepatolienal pendulum," a "Windkessel function," or a "pressure compensation." These studies were mainly published in German-speaking countries and have not, as far as is known, been discussed in the English-speaking world so far. Summary: This review explores the historical development of the rhythmical regulatory function of the spleen in the splanchnic region. Older studies and results are followed up
\end{abstract}

in the modern literature, wherever possible, up to the present. The clinical relevance is illustrated with portal hypertension (with congestive or hyperdynamic splenomegaly), coeliac disease, and chronic inflammatory bowel diseases (with functional hyposplenism). Key Message: The spleen's rhythmical regulatory function in nutrition is based on an autonomous rhythm comprising cycles of contractions and dilations of the spleen of around $1 \mathrm{~min}$. These cycles can be influenced by sympathetically mediated single contractions with a release of pooled blood or by portal vein congestion. After food ingestion, the spleen responds either with contraction according to a vasomotor reaction or postprandial congestion with significant increases in volume. The spleen's rhythmical function is lost in the clinical picture of portal hypertension or in coeliac disease and chronic inflammatory bowel diseases. In the aforementioned gastrointestinal diseases, we recommend taking more account of the haemodynamics between the spleen, liver, and intestine. New innovative techniques for recording splenograms are required which, besides elastographic measurements of spleen stiffness, could offer an important tool for early detection, diagnosis, and therapeutic evaluation.

(c) 2020 S. Karger AG, Base karger@karger.com

www.karger.com/dig

(C) 2020 S. Karger AG, Base

Karger"
Dr. Johannes Weinzirl

Institute for Integrative Medicine

Faculty of Health, Witten/Herdecke University

Gerhard Kienle Weg 4, DE-58313 Herdecke (Germany)

johannes.weinzirl@uni-wh.de 


\section{Introduction}

Before the spleen was recognized as a lymphatic organ with immunological and haematological functions, for thousands of years, it was considered to have a principal role in the digestive system [1]. Today, medical systems such as traditional Chinese medicine [2] and more recent integrative approaches such as anthroposophical medicine [3] postulate concepts of a regulative function of the spleen in nutrition $[4,5]$. Integration of these kinds of functional concepts and the therapeutic approaches arising from them only make sense when the anatomical and physiological basis is also researched as an integrative organology. We have recently reviewed the close phylogenetic, embryological, and anatomical connections between the spleen and the stomach with regard to a "splenogastric system," where direct communicating arteries and veins between the gastric fundus and the upper splenic pole have been rediscovered through modern surgery, thus reopening old questions from medical history about a direct secretory or resorptive function between the spleen and the stomach [6].

The herewith presented article aimed to focus on the dynamic interplay between the spleen and the gut and review the regulative functions of the spleen in relation to the splanchnic circulation in particular. We discuss postprandial haemodynamics and their clinical relevance, illustrated by splenomegaly in portal hypertension, as well as functional hyposplenism using inflammatory bowel diseases and coeliac disease as major examples.

\section{Methods}

We searched MEDLINE by combining the search terms "spleen," "splen*," "hyposplen*," and "hypersplen*" (in title) with the medical subject headings "Diet, Food, and Nutrition," "Digestive System and Oral Physiological Phenomena," and/or "Digestive System Diseases," as well as by using a combination of the search terms "rhythm," "dynamic*," "postprandial," and "food*." We selected relevant topics from the results by screening the abstracts and reference lists. We worked through 5 major book publications on the spleen and consulted 15 experts on anatomy, evolutionary biology, physiology, surgery, gastroenterology, and anthroposophical medicine. We organized 2 scientific conferences at Witten/Herdecke University, where we presented and discussed our intermediate results.

The rhythmical basis and the haemodynamics of the spleen in the splanchnic region were studied in the 19th and 20th centuries, particularly in German-speaking countries, and published mostly in the form of monographs. Citations of these articles and their bibliographies were followed up to the present day using

Splenic Rhythms and Postprandial Dynamics
Google Scholar and Elsevier Scopus. As far as we are aware, the physiological observations described in these publications are now made available to the English-speaking world for the first time.

\section{Results}

\section{Rhythmical Changes in Splenic Volume}

Depending on body size and sex, the mean splenic volume is $166 \mathrm{~cm}^{3}$ (5th/95th interpercentile range: $80-324$ $\mathrm{cm}^{3}$ ), with spleen length $10.9 \mathrm{~cm}$ (range: $8.7-13.3 \mathrm{~cm}$ ) showing the strongest correlation to spleen volume [7]. Even the earliest writings of the Corpus Hippocraticum state that the size of the spleen is not static but variable [8]. Spleen volume decreases by up to $40 \%$ during sports activities [9]; hypoxia, for example, in apnoeic diving [10]; and other physiological stressors and leads to a corresponding increase in the haematocrit and the oxygencarrying capacity of the blood [11]. Similarly, the spleen provides a reservoir function for platelets $(30 \%$ of the body reserve) and lymphocytes (40\% of the body reserve). An example of this is the remarkable splenic responses after a stroke. Splenic lymphocytes migrate to the infarct area to be involved in the poststroke inflammatory cascade, causing a drastic reduction in spleen volume [12]. These active, single contractions of the spleen provide a blood reservoir for the systemic circulation. Contractions are anatomically based on contractile proteins in the capsule and trabeculae of the spleen, as well as in the walls of arteries, veins, reticular cells of the white pulp, and sinuslining cells of the red pulp. They are mediated by alphaadrenergic fibres in the splenic nerve, which consists $98 \%$ of sympathetic nerve fibres and, therefore, can be therapeutically modulated using catecholamines $[11,12]$.

Active contractions must be distinguished from continuous, autonomous contractions and dilations of the spleen, which form a basic rhythm that was first discovered in animal experiments at the start of the 20th century. These experiments, first made by Roy [13], used surgically attached plethysmographs $[14,15]$ and graphically documented volume changes of the spleen by means of what are known as "splenograms" (Fig. 1). The regular "systoles and diastoles" of the spleen [13], later also called splenomotoric waves [16], appeared to be independent of other rhythms (pulse, breathing, blood pressure, and Traube-Hering-Mayer waves) and had period lengths of just under a minute $[15,17,18]$. The innervation and possible modulation by substances such as vasoconstrictors and vasodilators $[16,19-21]$, and the effects of physical 


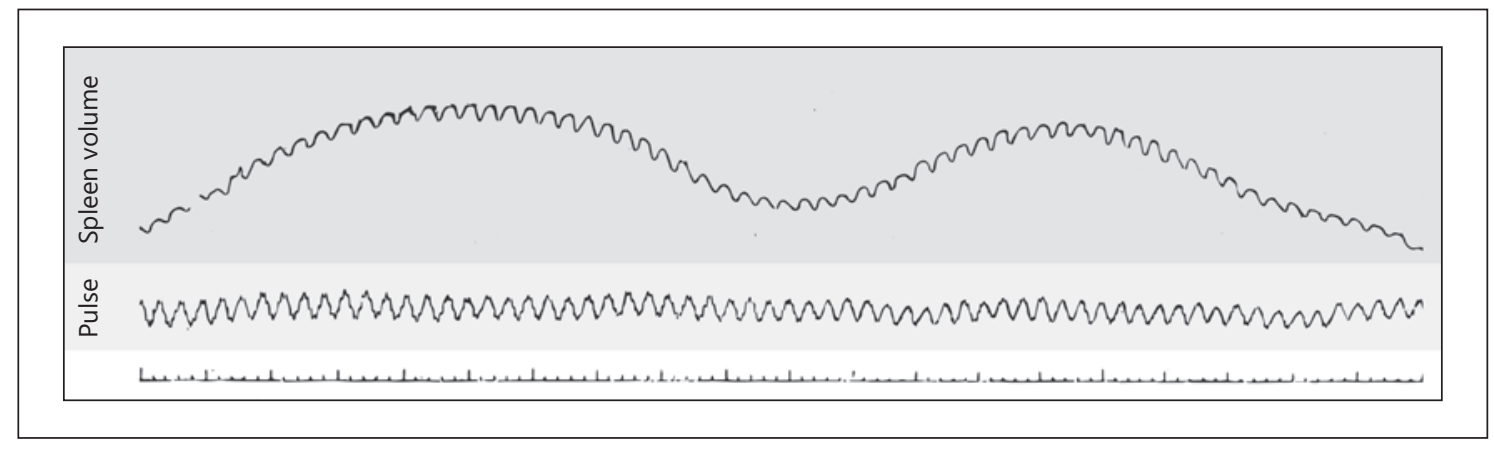

Fig. 1. Splenogram derived by plethysmography for a dog at rest. The figure shows the rhythmical spleen volume in relation to pulse and time in seconds. One spleen cycle (systole and diastole) lasts approximately $50 \mathrm{~s}$ and comprises smaller pulse oscillations. The magnitude of the amplitude in this 1905 study was not determined. Figure adapted from Ref. 17.

activity, breathing, and physiological and psychological stress on this basic rhythm were studied in detail $[19,22-$ 24].

In humans, the basic splenic rhythm was confirmed using the diagnostic procedure of splenoportography [25-27] in which the spleen was laparoscopically punctured and connected to a manometer. In healthy patients, Wannagat [28] observed continuous intrasplenic pressure fluctuations with period lengths of around $45 \mathrm{~s}$. He also noticed that under increasing portal pressure, the elasticity and rhythm of the spleen steadily diminished. In patients with chronic elevated portal hypertension, the rhythmical amplitude of the spleen dwindled to a fixed single-value curve and was accompanied clinically by a large and spongy congested spleen.

In conclusion, 3 causes for volume changes in the spleen need to be distinguished: (a) autonomous contractions and dilations of the spleen corresponding to a basic rhythm, (b) sympathetically mediated single contractions that provide the circulation with pooled blood, and (c) passive, that is, congestive, dilations from the portal vein system. These congestive dilations are related to the pressure and circulatory conditions of the splanchnic blood flow, which leads to the relationship between the spleen and nutritional metabolism.

\section{Changes in the Spleen after Ingestion}

Beginning in the first half of the 19th century, systematic studies on changes in spleen size after eating a meal were undertaken, prompted by the assumption of mechanical and chemical interactions between the stomach, liver, and spleen [29-31]. In postmortem examinations of dogs, guinea pigs, rabbits, and cats, enlarged spleens were observed up to several hours after food intake and studied in detail [29, 30, 32-36]. The anatomist Henry Gray [37], who was able to confirm postprandial spleen enlargement in 30 rabbits in his own dissertation, summarized the available literature in 1858 as follows: "The size of the spleen is increased during and after digestion" [38]. Similar remarks also appeared in physiological textbooks of the time [39].

Following the plethysmographic measurements, Hargis and Mann [40] evaluated the effect of food on variable spleen volume in dogs by means of splenograms. They confirmed a splenic rhythm with a mean contraction and dilation cycle of $47 \mathrm{~s}$ and were able to demonstrate for the first time a clear postprandial increase in spleen volume depending on the composition of the meal and lasting for several hours. The splenogram showed a higher amplitude after consuming animal fat (hog lard: peak after 40 min), protein-rich meat (lean beef: peak after $20 \mathrm{~min}$ ), and, to a lesser degree, carbohydrate (corn syrup: peak after $30 \mathrm{~min}$ ). Ingesting milk led to a temporary reduction in spleen volume.

\section{Postprandial Haemodynamics of the Spleen within the} Splanchnic Circulation

In order to explain these postprandial volume dynamics, studies were conducted on the relation of the spleen to the haemodynamics of the splanchnic circulation. The splanchnic circulation comprises the arterial and venous blood flow in the digestive system and displays interdependencies among peristalsis, the portal venous system, the liver, and the spleen $[41,42]$. If blood flow and pressure in the elastic mesenteric and portal vessels increase, the splenic artery reacts with vasoconstriction, leading to a reduced arterial blood supply $[43,44]$. Conversely, a decrease in the portal pressure leads to an opening of the 


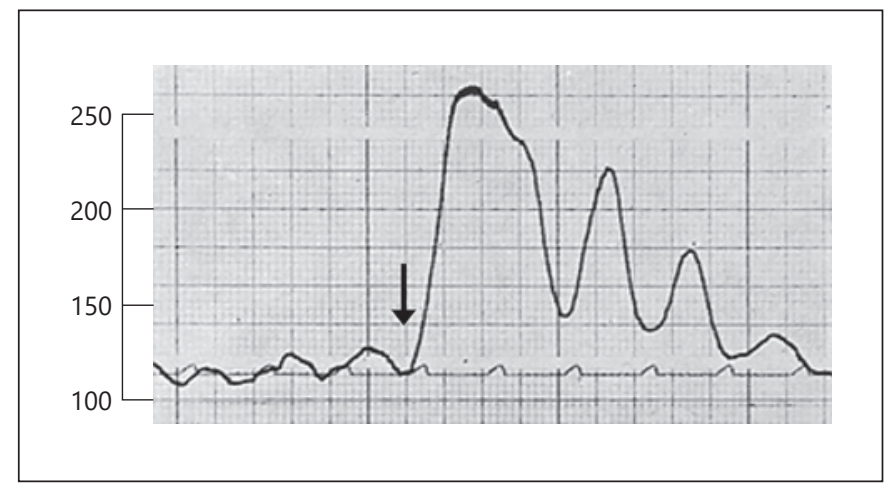

Fig. 2. Example of a venovasomotor reaction of the splenic circulation in a cat. With an increase in venous pressure (see arrow, increase of $33 \mathrm{~mm} \mathrm{Hg}$ ), the splenic artery contracts and shows an increased amplitude (pressure in $\mathrm{mm} \mathrm{Hg}$ ) and slightly decreased frequency. Figure adapted from Ref. 44.

arterial branch of the spleen. This "venovasomotor reflex" (Fig. 2) allows for a subtle balance between the portal pressure and the arterial blood flow in the spleen. A constant portal blood flow, particularly in the liver, can thus be guaranteed. Conversely, with increased portal pressure, the portal circulation can be relieved by reducing the splenic arterial flow. The spleen was, therefore, justifiably viewed as an important "regulatory factor in the portal system" [45].

After eating a meal, the splanchnic blood flow increases markedly by up to $200 \%$, depending on the quantity and composition of the food [46]. This postprandial hyperaemia leads to a sequential increase in blood flow in the mesenteric vessels and in the portal system, with a peak around $30 \mathrm{~min}$ after food intake $[46,47]$. Following the venovasomotor reflex, the spleen initially responds with a reduction in its arterial supply and an amplified and slower rhythm $[41,42]$.

If the increasing postprandial hyperaemia and dilatation of the portal vessels reach a critical point where the spleen cannot withstand the increased portal pressure, it swells from the venous side and suspends its rhythmicity $[41,45]$. In this second response, the spleen functions like an upstream "pressure reservoir" [41] which protects the liver and portal system from excessive overflow. This temporary venous congestion of the spleen continues until the hyperaemia has subsided. A wide range of 20thcentury authors have described this function of a "hepatolienal pendulum" [14] and, therefore, termed the spleen an "auxiliary motor" [48], a "pump" [42, 45], a "Windkessel function" [14], or, in analogy to the systemic circulation, an "elastic heart in the portal vein system" [49].

Splenic Rhythms and Postprandial Dynamics
We suggest that the postprandial enlargement of the spleen should be interpreted primarily as a portal pressure compensation and not a temporary reversal of the portal flow to the spleen, as some authors have postulated $[42,48]$. This difference seems important, as the portal blood does not flow towards the spleen but congests back due to the increased portal pressure.

Steiner and Kolisko postulated that the rhythmical function of the spleen with a compensative enlargement of the organ is primarily called upon for irregular food intake, that is, after meals at irregular times [50, 51]. Regular and timed meals lead to an anticipation of gastrointestinal motility, secretion, and increased activity of digestive enzymes [52,53]. It is quite conceivable that with untimed meals, the liver and portal system have greater demands placed on them and the spleen has to increase its balancing activity. This idea is put to use in the integrative concept of anthroposophical medicine [3], where regular low-fat and low-meat food with smaller snacks are recommended in order to decrease the demands on the spleen [4]. Further studies are required to evaluate the effect of regular and irregular food intake on the functioning of the spleen.

\section{Postprandial Changes in the Spleen in Modern \\ Imaging}

In the era of modern imaging techniques, there are 3 studies which have investigated volume changes in the spleen after food intake. Using single-photon emission computed tomography, Roshdy et al. [54] were able to detect a minimal but statistically significant decrease in spleen volume, averaging $3.2 \%$ in 20 healthy volunteers, $30-45$ min postprandially $(1,600 \mathrm{~kJ})$. Betal et al. [55] came to a similar result in their measurements on 10 healthy test subjects using magnetic resonance tomography; 30 $45 \mathrm{~min}$ after eating $(2,460 \mathrm{~kJ})$, they observed an average decrease in spleen volume of $6.6 \%$ [55]. The authors interpreted their results in terms of the venovasomotoric reaction with a reduction in arterial blood flow.

In our crossover study, 10 healthy test subjects were either randomly given a substantial meal $(3,600 \mathrm{~kJ})$ or kept fasting. Spleen volume was systematically followed using sonographic video measurements at 5 measurement points over $7 \mathrm{~h}$. Splenic volume increased significantly by $38.2 \pm 51.2 \mathrm{~cm}^{3}$ (17.3\%; $\left.p=0.04\right)$, with a peak $30 \mathrm{~min}$ after food intake. In males, splenic volume $30 \mathrm{~min}$ after a meal was $70.2 \pm 21.6 \mathrm{~cm}^{3}$ higher $(p=0.002)$ than that after the fasting condition, and 60 min later, it was still significantly increased. We interpreted these findings as postprandial congestion, where the spleen balances the 
increased portal hyperaemia through a temporary enlargement [56].

The recently available non-invasive technique of elastography allows the elastic properties and stiffness of the liver and spleen to be determined using ultrasound or magnetic resonance combined with a vibration module [57]. A postprandial increase in liver and spleen stiffness is well documented in patients with chronic liver disease and portal hypertension [58-60]. The increase in stiffness after food intake correlates with the stage of liver fibrosis and the increased portal flow (peak $30 \mathrm{~min}$ after food intake) [61]. Interestingly, a postprandial increase in liver stiffness $[57,62,63]$ and spleen stiffness [63] was also shown in healthy controls and in patients with only minor or no signs of liver fibrosis.

In summary, we suggest differentiating between 2 postprandial spleen reactions: in the case of a slight hyperaemia in the portal system, the spleen reacts with reduced arterial blood flow, enhanced rhythm, and a slight decrease in volume and stiffness. With a greater hyperaemia, such as after ingestion of a heavy meal, the increasing portal pressure leads to an increased stiffness of the spleen with a temporary loss of its rhythm and enlargement of the organ - this condition becomes chronic in the case of portal hypertension.

\section{The Spleen in Portal Hypertension}

Clinically, portal hypertension occurs when the pressure in the portal vein system exceeds the standard values (1-5 $\mathrm{mm} \mathrm{Hg}$ ) based on increased intrahepatic vascular resistance [64]. The most common causes worldwide are liver cirrhosis and schistosomiasis. Increasing complications arise with a portal pressure $>10 \mathrm{~mm} \mathrm{Hg}$. Associated risks are the formation of portosystemic collaterals that can lead to oesophageal and gastric varices with a high risk of bleeding and mortality [65].

The spleen plays an important part in the diagnosis and risk appraisal of portal hypertension. Elastographic studies of spleen stiffness and combined scores of spleen diameter, liver stiffness, and platelet count are considered to be a simple, non-invasive, and cost-effective alternative to oesophagogastroduodenoscopy and can assess the presence of oesophageal varices with high sensitivity and specificity [66-68]. Spleen stiffness also seems to be a significant and helpful parameter in the follow-up of patients with chronic hepatitis $\mathrm{C}$ or hepatocellular carcinoma $[69,70]$. Evaluation of basal rhythmical splenic contractions and dilatation could add to a sensitive instrument to record early changes in the splanchnic circulation and evaluate possible effects of medication. New and innova- tive approaches for a non-invasive modern splenogram are required and could be used in screening, diagnosis, and follow-up procedures.

The consequences of portal hypertension for the spleen appear in several stages. First, the spleen reacts according to the pressure compensation with splenomegaly, that is, a large, spongy congested spleen with loss of its rhythmical function in nutrition, increased volume, and increased tissue stiffness. Due to the prolonged congestion, further structural alterations occur with hypertrophy of the elastic contractile elements, thickening of the spleen capsule and trabecula, and an increase in the white pulp resulting from an immunological reaction with reticuloendothelial hyperplasia [71, 72]. Enlargement of the venous sinusoids leads to increased blood pooling and greater sequestration of platelets, erythrocytes, and leucocytes, producing a drop in all 3 cell populations in the peripheral blood count [72]. The formation of portosystemic collaterals appears to be helpful in relieving the portal vein system. However, the subsequent reduced splanchnic circulation leads to reactive splanchnic and systemic vasodilation $[73,74]$. Portal pressure and splenomegaly are then no longer based solely on congestion and increased intrahepatic resistance (backward theory) but maintained by a generally increased arterial supply (forward theory). In the final stage of this condition known as "hyperdynamic circulation," progressive vasodilation affects the whole circulatory system with low vascular resistance and increased cardiac output, all the way to multiple organ failure $[75,76]$.

In summary, splenomegaly in portal hypertension appears initially as a gradual loss of rhythm, venous congestion, and structural hyperplasia with pooling of the blood and finally as an overflow related to the hyperdynamic circulation. Further studies on these stages are required in order to define the transitions with regard to the rhythmical function of the spleen more clearly.

\section{Functional Hyposplenism in Coeliac Disease and Chronic Inflammatory Bowel Diseases}

Functional hyposplenism is defined as an impaired spleen function that is commonly associated with a small to atrophic spleen $[77,78]$. As in the case of asplenia, where the spleen is congenitally missing or absent due to surgical removal, hyposplenism leads to the risk of fulminant sepsis with high mortality (overwhelming postsplenectomy infection) due to reduced immune function. Suitable prophylactic management is recommended for hyposplenic patients $[77,79,80]$. 
Clinical diagnosis of hyposplenism is based on an assessment of the spleen's filtering function by radioisotopic methods [81] or quantitation of cell abnormalities in the peripheral blood smear [82]. Counting Howell-Jolly, Heinz, and Pappenheimer bodies is a reliable and established screening method for hyposplenic states. As their specificity and sensitivity have been disputed especially in mild forms of hyposplenism, some authors suggest pitted erythrocytes as the new gold standard [77]. Counting pitted erythrocytes (membrane abnormalities visible with phase-interference microscopy) is a simple, repeatable, and cost-efficient method of assessing hyposplenism [79, 83].

Coeliac disease is one of the most commonly associated underlying conditions of hyposplenism. Impaired spleen function occurs in 33-76\% of patients and correlates with the severity and complication rate [84]. As long as the spleen tissue is not totally destroyed, spleen function can be restored using a gluten-free diet [85]. Functional hyposplenism is also common in chronic inflammatory bowel diseases. It occurs in around up to a third of all patients with ulcerative colitis and, although less frequently, in Crohn's disease [84]. In these cases, impaired spleen function and size are again dependent on the severity of the disease, and complications such as perforations, fistulas, abscesses, bleeding, and toxic megacolon have been more frequently observed in conjunction with a small spleen [78]. Interestingly, functional hyposplenism also occurs in patients under long-term parenteral nutrition, where the length of the intravenous nutrition is correlated with the percentage of pitted red cells [86].

As far as known, there are no studies to date on the relationship between splanchnic haemodynamics, spleen rhythm, and functional hyposplenism. However, some preliminary indirect data are available. Patients with active untreated coeliac disease, ulcerative colitis, and Crohn's disease demonstrate a significantly increased blood flow in the mesenteric and portal vessels and correspondingly lower resistance indexes [87-90]. Magalotti et al. [91] studied this hyperdynamic splanchnic circulation, for example, in coeliac patients before and after eating a meal and were able to demonstrate a reduced and delayed postprandial hyperaemia. They found that 60 min after food intake $(800 \mathrm{kcal})$, the blood flow in the portal vein increased by $97 \%$ in the control group but in the coeliac group by only $49 \%$ and remained increased for $3 \mathrm{~h}$ after eating, unlike the control group.

Considering the rhythmical function of the spleen, it is quite remarkable that if postprandial hyperaemia is reduced (e.g., in coeliac disease) or completely absent (in parenteral nutrition), an impaired spleen function results in the long term. It seems most likely that the rhythmical function of the spleen - in a similar way to portal congestion - is also suspended in functional hyposplenism, thus initiating the loss of the organ's function. A continuous evaluation of the rhythmical function by means of splenograms could be of great significance for the early pathogenesis and therapeutic modulation of the disease. We would like to recommend that, besides the immunological interactions, further studies should pay more attention to these haemodynamic relationships between the spleen and the intestine.

\section{Discussion}

This review considers the spleen to be a rhythmical regulatory and balancing organ in 2 ways. As part of a functional unit with the splanchnic circulation, the spleen reacts to the pressure and circulatory conditions in the portal vein system and guarantees a constant portal flow (venovasomotor reflex). As part of a functional unit with the digestive tract, the spleen balances the postprandial hyperaemia via temporary enlargement of the organ (postprandial congestion). The spleen can, therefore, be described as a regulative organ for the nutritional system.

Innovative ways of assessing the rhythmical spleen function are now required in which postprandial congestion must be distinguished from sympathetically modulated stress contractions. What is particularly interesting about the postprandial congestion is when and how the change to enlargement of the organ occurs.

In nutritional studies, the type, quantity, and composition of the food appear to be crucial for the magnitude of the splanchnic blood flow. Stronger spleen reactions are to be expected from solid, calorie-rich food than with smaller meals with liquid, low-calorie, and low-fat food. The hypothesis that irregular food intake results in greater postprandial blood flow and spleen reactions than with timed meals also needs further study. It should be noted for all these investigations that the spleen is exceptionally sensitive to respiration. Breathing manoeuvres (e.g., in imaging methods) must be avoided because even short apnoeas lead to sympathetically mediated single contractions to provide the circulation with pooled blood [92].

In terms of clinical research, more studies are required on the early signs and gradual loss of the rhythmical spleen function, all the way to splenomegaly in portal hypertension or to functional hyposplenism such as in coeliac disease and chronic inflammatory bowel diseases. 
Investigations on therapeutic modulations of the splenic rhythm should focus on both pharmacological approaches and the patient's psychosocial dimension as the original splenograms showed clear splenic responses to psychological factors such as anxiety and stress $[14,40]$. mend taking more account of the haemodynamics between the spleen, liver, and intestine. New innovative techniques for recording splenograms are required which, besides elastographic measurements of spleen stiffness, could offer an important tool for early detection, diagnosis, and therapeutic evaluation.

\section{Disclosure Statement}

The authors declare that they have no conflict of interest. The study was not influenced by the foundations that provided financial support.

\section{Funding Sources}

We gratefully acknowledge the financial support of the Christophorus Stiftung and the Software AG Stiftung.

\section{Author Contributions}

All authors made substantial contributions to the conception of this review. J.W. wrote the final manuscript, which was reviewed, edited, and revised by L.G., T.S., L.A., and P.H.

eliac disease and chronic inflammatory bowel diseases. the aforementioned gastrointestinal diseases, we recom-

\section{References}

1 McClusky DA, Skandalakis LJ, Colborn GL, Skandalakis JE. Tribute to a triad: history of splenic anatomy, physiology, and surgery: part 1. World J Surg. 1999;23(3):311-25.

2 Patwardhan B, Warude D, Pushpangadan P, Bhatt N. Ayurveda and traditional Chinese medicine: a comparative overview. Evid Based Complement Alternat Med. 2005;2(4): 465-73.

3 Kienle GS, Albonico HU, Baars E, Hamre HJ, Zimmermann P, Kiene H. Anthroposophic medicine: an integrative medical system originating in europe. Glob Adv Health Med. 2013 Nov;2(6):20-31.

4 Weinzirl J, Scheffers T, Garnitschnig L, Heusser P. Die Milz in Natur- und Geisteswissenschaft. Merkurstab. 2018;2:110-9.

5 Yang X, Jia C. Understanding association of spleen system with earth on traditional Chinese medicine theory. J Tradit Chin Med. 2013;33(1):134-6.

6 Weinzirl J, Scheffers T, Garnitschnig L, Andrae L, Heusser P. Does the Spleen Have a Function in Digestion? Medical History, Phylogenetic and Embryological Development of the Splenogastric System. Complement Med Res. 2020:1-7. http://dx.doi.org/10.1159/ 000506390.

7 Chow KU, Luxembourg B, Seifried E, Bonig H. Spleen size is significantly influenced by body height and sex: establishment of normal values for spleen size at US with a cohort of 1,200 healthy individuals. Radiology. 2015 Oct:279(1):306-13.

8 Hippokrates. Viertes Buch über die Krankheiten. Hippocrates Werke: Aus dem Griechischen übersetzt und mit Erläuterungen von J. F. C. Grimm. Glogau: H. Prausnitz; 1838.

9 Stewart IB, McKenzie DC. The human spleen during physiological stress. Sports Med. 2002; 32(6):361-9.

10 Baković D, Valic Z, Eterović D, Vuković I, Obad A, Marinović-Terzić I, et al. Spleen volume and blood flow response to repeated breath-hold apneas. J Appl Physiol. 2003 Jan; 95(4):1460-6.

11 Shephard RJ. Responses of the human spleen to exercise. J Sports Sci. 2016 May;34(10): 929-36.

12 Liu ZJ, Chen C, Li FW, Shen JM, Yang YY, Leak RK, et al. Splenic responses in ischemic stroke: new insights into stroke pathology. CNS Neurosci Ther. 2015 Apr;21(4):320-6.

13 Roy CS. The physiology and pathology of the spleen: first communication. J Physiol. 1882; 3(3-4):203-11.

14 Henschen C, Reissinger $H$. Beiträge zur klinischen Physiologie der Milz: Experimentelle Untersuchungen über die Volumenschwankungen und die Kontraktilität der
Milz, über ihre Durchblutung und über die Sperrmechanismen der Milzarterie. Dtsch Z Für Chir. 1928 Jul;210(1-4):1-35.

15 Schäfer EA, Moore B. On the contractility and innervation of the spleen. J Physiol. 1896; 20(1):1-50.

16 Lutz J, Bauereisen E. Abdominalorgane. Lehrbuch der Physiologie in Einzeldarstellungen. Berlin, Heidelberg: Springer; 1971.p. 229-92.

17 Strasser A, Wolf $\mathrm{H}$. Über die Blutversorgung der Milz. Arch Für Gesamte Physiol Menschen Tiere. 1905 Jun;108(10-12):590-626.

18 Barcroft J, Khanna LC, Nisimaru Y Rhythmical contraction of the spleen. J Physiol. 1932 Mar;74(3):294-8.

19 Grindlay JH, Herrick JF, Baldes EJ. Rhythmicity of the spleen in relation to blood flow. Am J Physiol. 1939 Jul;127(1):119-26.

20 Ross G. The regional circulation. Annu Rev Physiol. 1971;33(1):445-78

21 Reilly FD. Innervation and vascular pharmacodynamics of the mammalian spleen. Experientia. 1985 Feb;41(2):187-92.

22 Skramlik E. Die Milz. Ergebnisse der Biologie. Berlin, Heidelberg: Springer; 1927.p. 505-53.

23 McNee JW. The spleen: its structure and functions. Postgrad Med. 1931 May;43(5): 126-31.

24 Tischendorf F. Die Milz. Berlin, Heidelberg: Springer; 1969. 
25 Atkinson M, Sherlock S. Intrasplenic pressure as index of portal venous pressure. Lancet. 1954 Jun;266(6826):1325-7.

26 Wannagat L. Die laparoskopische Splenoportographie. Klin Wochenschr. 1955 Aug, 33(31-32):750-8

27 Sotgiu G, Cacciari C. Splenoportographie und Splenomanometrie. 60. Kongress. Munich: J.F. Bergmann-Verlag; 1954. p. 649-58.

28 Wannagat L. Zur Pathophysiologie der Menschenmilz. Leber und Milz: 4. Lebertagung der Sozialmedizin Bad Mergentheim. Stuttgart: Thieme; 1967.p. 55-70.

29 Giesker J. Splenologie: anatomisch-physiologische Untersuchungen über die Milz des Menschen. Zürich: Orell; 1835.

30 Landis J. Beiträge zur Lehre über die Verrichtungen der Milz. Zürich: Friedrich Schulthess; 1847.

31 Meckel J. Besondere Anatomie. Eingeweidelehre und Geschichte des Foetus. Halle, Berlin: Buchhandlung des Hallischen Waisenhauses; 1820.

32 Dobson W. An experimental inquiry into the structure and function of the spleen. London: Goyder; 1830

33 Dittmar A. Über periodische Volumsveränderungen der menschlichen Milz. Gießen: Wilhelm Keller; 1850.

34 Stinstra G. Commentatio physiologica de Functione lienis. Groningen: Wolters; 1854.

35 Leuret F, Lassaigne J-L. Recherches physiologiques et chimiques pour servir à l'histoire de la digestion. Paris: Huzard; 1825.

36 Schönfeld F. De functione lienis. Groningen: Wolters; 1855.

37 Gray H. On the structure and use of the spleen. London: J.W. Parker and Son; 1854.

38 Gray H. Anatomy: descriptive and surgical. 1st ed. London: J.W. Parker and Son; 1858.

39 Huxley TH. Lessons in elementary physiology. London: Macmillan and Company; 1869.

40 Hargis EH, Mann FC. A plethysmographic study of the changes in the volume of the spleen in the intact animal. Am J Physiol. 1925; $75: 180-200$

41 Ewerbeck H. Die Milz als Organ des Pfortadersystems und ihr Versagen. Ergebnisse der Inneren Medizin und Kinderheilkunde. Berlin, Göttingen, Heidelberg: Springer; 1949.

42 Guillery H. Die hämodynamische Bedeutung der Milz und ihres Blutes für den Pfortaderkreislauf. Z Für Gesamte Exp Med. 1938; 102(1):263-84

43 Schneider M. Zur Kreislauffunktion der Milz. Leber und Milz: 4. Lebertagung der Sozialmedizin Bad Mergentheim. Stuttgart: Thieme; 1967. p. 48-55.

44 Lutz J, Henrich H, Peiper U, Bauereisen E. Autoregulation und veno-vasomotorische Reaktion im Milzkreislauf. Pflüg Arch. 1969 Sep;313(3):271-88.

45 Streicher H-J. Chirurgie der Milz. Berlin, Göttingen, Heidelberg: Springer; 1961.

46 Matheson PJ, Wilson MA, Garrison RN. Regulation of intestinal blood flow. J Surg Res. 2000;93(1):182-96.
47 Someya N, Endo MY, Fukuba Y, Hayashi N Blood flow responses in celiac and superior mesenteric arteries in the initial phase of digestion. Am J Physiol Regul Integr Comp Physiol 2008 Jun;294(6):R1790-6.

48 Gorjajew N. Die Milz: ein contractiles Blutreservoir. Z Für Gesamte Exp Med. 1932 Dec; 85(1):723-30

49 Ewerbeck H. Der Symptomenkomplex der "dynamischen Milzdekompensation". Z Für Kinderheilkd. 1947 Jan;65(3):228-46.

50 Steiner R. Geisteswissenschaft und Medizin. 8. Aufl. (2020). Dornach: Rudolf Steiner Verlag; 1920.

51 Kolisko L. Milzfunktion und Plättchenfrage. Stuttgart: Kommender Tag A.G.; 1922.

52 Froy $\mathrm{O}$. The relationship between nutrition and circadian rhythms in mammals. Front Neuroendocrinol. 2007 Aug;28(2-3):61-71.

53 Asher G, Sassone-Corsi P. Time for food: the intimate interplay between nutrition, metabolism, and the circadian clock. Cell. 2015 Mar; 161(1):84-92.

54 Roshdy MS, Larsson SA, Kimiaei S, Jacobsson $H$. Effect of food intake on liver and spleen volume: assessment with single photon emission computed tomography. Acad Radiol. 1997;4(3):193-6.

55 Betal D, Hughes ML, Whitehouse GH, Roberts N. Postprandial decrease in splenic volume demonstrated by magnetic resonance imaging and stereology. Clin Anat. 2000;13(6):404-9.

56 Garnitschnig L, Weinzirl J, Andrae L, Scheffers T, Ostermann T, Heusser P. Postprandial dynamics of splenic volume in healthy volunteers. Physiol Rep. 2020;8:e14319.

57 Yin M, Talwalkar JA, Glaser KJ, Venkatesh SK, Chen J, Manduca A, et al. Dynamic postprandial hepatic stiffness augmentation assessed with MR elastography in patients with chronic liver disease. AJR Am J Roentgenol. 2011 Jul;197(1):64-70.

58 Mederacke I, Wursthorn K, Kirschner J, Rifai $\mathrm{K}$, Manns MP, Wedemeyer H, et al. Food intake increases liver stiffness in patients with chronic or resolved hepatitis $\mathrm{C}$ virus infection. Liver Int. 2009 Nov;29(10):1500-6.

59 Ratchatasettakul K, Rattanasiri S, Promson K, Sringam P, Sobhonslidsuk A. The inverse effect of meal intake on controlled attenuation parameter and liver stiffness as assessed by transient elastography. BMC Gastroenterol. 2017 Dec;17(1):50.

60 Berzigotti A, De Gottardi A, Vukotic R, Siramolpiwat S, Abraldes JG, García-Pagan JC, et al. Effect of meal ingestion on liver stiffness in patients with cirrhosis and portal hypertension. PLoS One. 2013;8(3):e58742.

61 Chin JL, Farrelly A, Chan G, Norris S, McCormick PA. Liver stiffness changes during meal times. Hepatology. 2014 Jul;60(1):432.

62 Barone M, Iannone A, Brunetti ND, Sebastiani F, Cecere O, Berardi E, et al. Liver stiffness and portal blood flow modifications induced by a liquid meal consumption: pathogenetic mechanisms and clinical relevance. Scand J Gastroenterol. 2015;50(5):560-6.
63 Kjærgaard M, Thiele M, Jansen C, Stæhr Madsen B, Görtzen J, Strassburg C, et al. High risk of misinterpreting liver and spleen stiffness using 2D shear-wave and transient elastography after a moderate or high calorie meal. PLoS One. 2017 Apr;12(4):e0173992.

64 Bosch J, Abraldes JG, Berzigotti A, García-Pagan JC. The clinical use of HVPG measurements in chronic liver disease. Nat Rev Gastroenterol Hepatol. 2009;6(10):573-82.

65 Garcia-Tsao G, Sanyal AJ, Grace ND, Carey W. Prevention and management of gastroesophageal varices and variceal hemorrhage in cirrhosis. Hepatology. 2007;46(3):922-38.

66 Ma X, Wang L, Wu H, Feng Y, Han X, Bu H, et al. Spleen stiffness is superior to liver stiffness for predicting esophageal varices in chronic liver disease: a meta-analysis. PLoS One. 2016 Nov;11(11):e0165786.

67 Colli A, Gana JC, Yap J, Adams-Webber T, Rashkovan N, Ling SC, et al. Platelet count, spleen length, and platelet count-to-spleen length ratio for the diagnosis of oesophageal varices in people with chronic liver disease or portal vein thrombosis. Cochrane Database Syst Rev, 2017 Apr;4:CD008759.

68 Manatsathit W, Samant H, Kapur S, Ingviya T, Esmadi M, Wijarnpreecha K, et al. Accuracy of liver stiffness, spleen stiffness, and LSspleen diameter to platelet ratio score in detection of esophageal varices: systemic review and meta-analysis. J Gastroenterol Hepatol. 2018 May;33(10):1696-706

69 Marasco G, Colecchia A, Colli A, Ravaioli F, Casazza G, Bacchi Reggiani ML, et al. Reply to correspondence concerning: "role of liver and spleen stiffness in predicting the recurrence of hepatocellular carcinoma after resection". J Hepatol. 2018 Oct;70(4):809-10.

70 Ravaioli F, Colecchia A, Dajti E, Marasco G, Alemanni LV, Tamè M, et al. Spleen stiffness mirrors changes in portal hypertension after successful interferon-free therapy in chronichepatitis C virus patients. World J Hepatol. 2018 Oct;10(10):731-42.

71 Kondo $\mathrm{R}$, Kage $\mathrm{M}$, Iijima $\mathrm{H}$, Fujimoto J, Nishimura T, Aizawa N, et al. Pathological findings that contribute to tissue stiffness in the spleen of liver cirrhosis patients. Hepatol Res. 2018 Jun;48(12);1000-7.

72 Bolognesi M, Merkel C, Sacerdoti D, Nava V, Gatta A. Role of spleen enlargement in cirrhosis with portal hypertension. Dig Liver Dis. 2002 Feb;34(2):144-50.

73 MacMathuna P, Vlavianos P, Westaby D, Williams R. Pathophysiology of portal hypertension. Dig Dis. 1992;10(Suppl 1):3-15.

74 Iwakiri Y, Groszmann RJ. The hyperdynamic circulation of chronic liver diseases: from the patient to the molecule. Hepatology. 2006; 43(2 Suppl 1):S121-31.

75 García-Pagán JC, Gracia-Sancho J, Bosch J. Functional aspects on the pathophysiology of portal hypertension in cirrhosis. J Hepatol. 2012 Aug;57(2):458-61. 
76 Bosch J, Groszmann RJ, Shah VH. Evolution in the understanding of the pathophysiological basis of portal hypertension: how changes in paradigm are leading to successful new treatments. J Hepatol. 2015 Apr;62(Suppl 1): S121-30.

77 Di Sabatino A, Carsetti R, Corazza GR. Postsplenectomy and hyposplenic states. Lancet. 2011;378(9785):86-97.

78 William BM, Corazza GR. Hyposplenism: a comprehensive review. Part I: basic concepts and causes. Hematology. 2007;12(1):1-13.

79 William BM, Thawani N, Sae-Tia S, Corazza GR. Hyposplenism: a comprehensive review. Part II: clinical manifestations, diagnosis, and management. Hematology. 2007;12(2):89-8.

80 Simons M, Scott-Sheldon LAJ, Risech-Neyman Y, Moss SF, Ludvigsson JF, Green PHR. Celiac disease and increased risk of pneumococcal infection: a systematic review and meta-analysis. Am J Med. 2018 Jan;131(1):83-9.

81 Spencer RP, Gupta SM, Hansell JR. The spleen: diagnosis of splenic diseases using radiolabeled tracers. Crit Rev Clin Lab Sci. 1989; 27(4):299-318.
82 Mohamed M. Functional hyposplenism diagnosed by blood film examination. Blood. 2014 Sep;124(12):1997.

83 Corazza GR, Bullen AW, Hall R, Robinson PJ, Losowsky MS. Simple method of assessing splenic function in coeliac disease. Clin Sci. 1981;60(1):109-13.

84 Muller AF, Toghill PJ. Hyposplenism in gastrointestinal disease. Gut. 1995;36(2):165-7.

85 Di Sabatino A, Brunetti L, Carnevale Maffè G, Giuffrida P, Corazza GR. Is it worth investigating splenic function in patients with celiac disease? World J Gastroenterol. 2013 Apr; 19(15):2313-8.

86 Zoli G, Corazza GR, Wood S, Bartoli R, Gasbarrini G, Farthing MJ. Impaired splenic function and tuftsin deficiency in patients with intestinal failure on long term intravenous nutrition. Gut. 1998;43(6):759-62.

87 Arienti V, Califano C, Brusco G, Boriani L, Biagi F, Giulia Sama M, et al. Doppler ultrasonographic evaluation of splanchnic blood flow in coeliac disease. Gut. 1996 Sep;39(3): $369-73$.
88 Aliotta A, Pompili M, Rapaccini GL, De Vitis I, Caputo S, Cedrone A, et al. Doppler ultrasonographic evaluation of blood flow in the superior mesenteric artery in celiac patients and in healthy controls in fasting conditions and after saccharose ingestion. J Ultrasound Med. 1997 Feb;16(2):85-4.

89 Bolondi L, Gaiani S, Brignola C, Campieri M, Rigamonti A, Zironi G, et al. Changes in splanchnic hemodynamics in inflammatory bowel disease. Non-invasive assessment by Doppler ultrasound flowmetry. Scand J Gastroenterol. 1992 Jun;27(6):501-7.

90 Di Sabatino A, Armellini E, Corazza GR. Doppler sonography in the diagnosis of inflammatory bowel disease. Dig Dis. 2004; 22(1):63-6

91 Magalotti D, Volta U, Bonfiglioli A, Ramilli S, Berzigotti A, Zoli M. Splanchnic haemodynamics in patients with coeliac disease: effects of a gluten-free diet. Dig Liver Dis. 2003 Apr; $35(4): 262-8$.

92 Inoue Y, Nakajima A, Mizukami S, Hata $\mathrm{H}$. Effect of breath holding on spleen volume measured by magnetic resonance imaging. PLoS One. 2013;8(6):e68670. 